\title{
Differential selectivity of CIITA promoter activation by IFN- $\gamma$ and IRF-1 in astrocytes and macrophages: CIITA promoter activation is not affected by TNF- $\alpha$
}

\author{
Kelly M. Nikcevich, Janet F. Piskurich, Ronald P. Hellendall, Ying Wang, Jenny P.-Y. Ting \\ University of North Carolina Lineberger Comprehensive Cancer Center, Department of Microbiology-Immunology, \\ University of North Carolina-Chapel Hill, Chapel Hill, NC 27599-7295, USA
}

Received 30 March 1999; received in revised form 7 June 1999; accepted 7 June 1999

\begin{abstract}
During demyelinating disease of the central nervous system (CNS), locally elevated cytokine levels may induce upregulation of MHC class II molecules on otherwise low expressing or negative cell types such as microglia and astrocytes, since IFN- $\gamma$ has been shown to induce MHC class II expression on these cell types in vitro. While many transcription factors are involved with MHC class II expression, only the class II transactivator (CIITA) is tightly coordinated with IFN- $\gamma$-inducibility. Control of CIITA gene expression is complex, involving four distinct promoters, two of which (promoters III and IV) are IFN- $\gamma$-inducible in certain cell types. Here we demonstrate that IFN- $\gamma$ treatment of rat astrocytes induces only CIITA promoter IV activity in contrast to the murine macrophage cell line RAW 264.7 that uses both IFN- $\gamma$-inducible promoters. In contrast to previously published reports, promoter IV activation is completely dependent upon an intact interferon regulatory factor-1 (IRF-1) but not STAT1 binding site using promoter constructs specifically mutated at these positions. Importantly, while TNF- $\alpha$ is able to synergize with IFN- $\gamma$ to increase astrocyte MHC class II expression in vitro, we show that treatment of rat astrocytes with TNF- $\alpha$ has no effect on CIITA promoter activity. These data demonstrate that TNF- $\alpha$ augments MHC class II expression through a mechanism downstream or independent of CIITA induction. (C) 1999 Elsevier Science B.V. All rights reserved.
\end{abstract}

Keywords: Brain; EAE/MS; Neuroimmunology; MHC; Transcription factors

\section{Introduction}

Diseases of the central nervous system (CNS) are often characterized by the presence of activated glial cells around areas of demyelination. Several published reports have demonstrated a direct correlation between the level of MHC class II expression on cells of the CNS and the susceptibility to demyelinating disease in a number of different laboratory models (Massa et al., 1987a,b; Male and Pryce, 1989; Birnbaum and Kotilinek, 1990; Borrow and Nash, 1992). Massa et al. (1987b) demonstrated that rat strains exhibiting hyperinducible MHC class II expression on astrocytes were more susceptible to the induction of experimental autoimmune encephalomyelitis. This cor-

\footnotetext{
* Corresponding author. Tel.: + 1-919-9665538; fax: + 1-919-9668212; E-mail: panyun@med.unc.edu (J. Ting)
}

relation has been demonstrated for cerebral vascular endothelial cells in the Theiler's murine encephalomyelitis virus-induced demyelinating model (Male and Pryce, 1989; Welsh et al., 1993), as well. Data from our laboratory has shown that the role of MHC class II expression in disease severity can also be extended to a non-T-cell-mediated model for demyelination (Matsushima et al., 1994). When Twitcher mice (a model for globoid cell leukodystrophy exhibiting spontaneous demyelination) were bred onto a MHC class II knockout background they exhibited significantly reduced twitching and demyelination providing evidence that MHC class II may perform functions other than simply presenting antigen to T-cells (Matsushima et al., 1994). Together, these data demonstrate a diverse role for MHC class II molecules during CNS disease pathogenesis.

The ability to therapeutically downregulate MHC class II during CNS demyelinating disease is an issue of great importance. While several groups have demonstrated that 
the systemic administration of anti-MHC class II antibodies resulted in improved prognosis for animals in which demyelination had been induced (Sriram and Steinman, 1983; Sriram et al., 1987; Friedmann et al., 1987; Jonker et al., 1988; Steinman, 1990; Smith et al., 1994), this treatment regimen did not specifically target MHC class II expressed in the CNS. The ability to specifically downregulate MHC class II expression on cells of the CNS would be a powerful tool for improving disease prognosis in individuals affected by demyelinating disease without affecting peripheral immune function. Thus, defining the molecular control of MHC class II expression on brain glial cells such as astrocytes is central to our understanding of how to therapeutically target MHC class II expression in the CNS.

Astrocytes are parenchymal cells constituting the largest population of cells of the CNS. A number of different in vitro stimuli are capable of inducing an activated phenotype in astrocytes including the proinflammatory cytokines IFN- $\gamma$ and TNF- $\alpha$ (Wong et al., 1984; Fierz et al., 1985; Fontana et al., 1986; Benveniste et al., 1989). Damage to the CNS in vivo caused by ischemia, viral infection, or injury also serves to activate astrocytes leading to increased production of immune effector molecules such as TNF- $\alpha$, TGF- $\beta$, IL-1, IL-3, PGE ${ }_{2}, \mathrm{LTB}_{4}$, IL-6, and IFN $\alpha / \beta$ (Fontana et al., 1983; Frei et al., 1985, 1989; Tedeschi et al., 1986; Robbins et al., 1987; Hartung et al., 1988; Sawada et al., 1989; Hailer et al., 1998). Similar to many other cell types, surface expression of MHC class II is upregulated on astrocytes following in vitro exposure to IFN- $\gamma$ (Wong et al., 1984; Moses et al., 1991) and this expression is further augmented in the presence of TNF- $\alpha$ (Benveniste et al., 1989). Most studies of MHC class II gene regulation have been conducted using B-cell or macrophage cell lines, however, the molecular control of expression is not completely understood. It is possible that cell type-specific regulation of $\mathrm{MHC}$ class II genes may exist as reflected by the varied activation of MHC class II by different cytokines.

Previous studies from our laboratory and others have indicated that the regulation of MHC class II is primarily controlled at the transcriptional level by a number of different DNA binding proteins including NF-Y and RFX (reviewed in Glimcher and Kara (1992)). These factors are ubiquitously expressed and are not regulated by IFN- $\gamma$. Another molecule, the class II transactivator (CIITA), is coordinately regulated with MHC class II in response to IFN- $\gamma$ (Steimle et al., 1994). The CIITA is a master regulator of all $\mathrm{MHC}$ class II genes including Ii and $\mathrm{H}-2 \mathrm{M}$ gene products important for the exogenous pathway of antigen processing (Chang and Flavell, 1995). CIITA per se is not a DNA-binding protein, rather it is thought to act indirectly on the MHC class II promoter by interacting with an as yet undefined DNA binding protein, although recent evidence has suggested interactions with RFX5, CBP, and Bob1 (Riley et al., 1995; Fontes et al., 1996;
Scholl et al., 1997; Kretsovali et al., 1998). The expression of CIITA is regulated at the transcriptional level through the action of four distinct promoters (Muhlethaler-Mottet et al., 1997) that play a significant role in determining tissue-specific expression of CIITA and therefore of MHC class II. CIITA promoter I-driven transcripts are found in dendritic cells while promoter III drives constitutive expression in B-cells (Lennon et al., 1997; Muhlethaler-Mottet et al., 1997). Promoter IV was initially thought to be solely responsible for the IFN- $\gamma$-inducible expression of CIITA (Muhlethaler-Mottet et al., 1997) and is active in many non-professional antigen presenting cells (APCs) leading to IFN- $\gamma$-inducible expression of MHC class II. More recent work from our laboratory has demonstrated an IFN- $\gamma$-inducible element in promoter III as well, located 2.5-kb upstream of the transcriptional start site, indicating a role for this promoter in the cytokine induction of $\mathrm{MHC}$ class II activation (Piskurich et al., 1998). Finally, we also found that TGF- $\beta$ downregulates the IFN- $\gamma$ activation of both promoters III and IV (Piskurich et al., 1998).

Less is known regarding the regulation of MHC class II gene expression in the CNS at the molecular level. Several lines of evidence have demonstrated differential MHC class II protein expression in response to various cytokines and effector molecules by astrocytes and microglia, suggesting that there are cell-specific differences in $\mathrm{MHC}$ class II gene regulation even within the same tissue (Hellendall and Ting, 1997; Sasaki et al., 1989, 1990). Here we investigate the regulation of CIITA expression in primary rat astrocytes in an effort to define these differences. Using various CIITA promoter/luciferase reporter constructs we have determined that promoter IV is the only active promoter in primary rat astrocytes following IFN- $\gamma$ stimulation. This is in contrast to the murine macrophage cell line RAW 264.7 in which IFN- $\gamma$-inducible promoter III is also active. We extend these findings to demonstrate that CIITA promoter IV activity in rat astrocytes is dependent upon the interferon regulatory factor-1 (IRF-1) binding site but is not dependent upon the STAT 1-binding site, in contrast to previously published reports of other cells (Muhlethaler-Mottet et al., 1998). The inclusion of TNF- $\alpha$ or neutralizing anti-TGF- $\beta$ antibodies in the astrocyte cultures had minimal effect on CIITA promoter activity suggesting that: (a) augmentation of MHC class II induction by TNF- $\alpha$ must occur at a point downstream of CIITA induction or is independent of CIITA induction, and (b) endogenous TGF- $\beta$ does not account for the lack of CIITA promoter III activity in astrocytes.

\section{Methods}

\subsection{Rats}

Timed pregnant Sprague-Dawley rats were purchased from Charles River (Wilmington, MA). Rats were main- 
tained in a specific pathogen-free environment in the University of North Carolina animal facility until delivery of the pups. One-day-old rat pups were used for isolation of astroglial cultures.

\subsection{Media and cell lines}

Astroglial cells were maintained in Dulbecco's modified Eagles medium (DMEM)/Ham's F12 (1:1) medium (Gibco BRL, Gaithersburg, MD) supplemented with $10 \%$ FBS (Sigma, St. Louis, MO), $100 \mathrm{U} / \mathrm{ml}$ penicillin (Gibco), and $100 \mu \mathrm{g} / \mathrm{ml}$ streptomycin (Gibco). The murine macrophage cell line, RAW 264.7, were maintained in RPMI (Gibco) supplemented with $2 \mathrm{mM}$ L-glutamine, and FBS, penicillin, and streptomycin as above.

\subsection{Cytokines and antibodies}

Recombinant rat IFN- $\gamma$, recombinant mouse IFN- $\gamma$, and recombinant mouse $\mathrm{TNF}-\alpha$ (which is cross reactive on rat cells) were purchased from Genzyme (Cambridge, MA). Anti-TGF- $\beta$, purchased from Genzyme, recognizes TGF$\beta_{1}$, TGF- $\beta_{2}$, and TGF- $\beta_{3}$ isoforms. Each cytokine or antibody was used at the concentrations indicated in the figure legends.

\subsection{Astroglial cell isolation}

Enriched cortical astrocyte cultures were prepared following the protocol of McCarthy and De Vellis (1980). Briefly, the brain was removed from one-day-old neonatal Lewis rats, the hind brain was dissected away and the meninges were removed. The left and right hemispheres were transferred to a culture dish containing medium and the cells were gently dissociated. Cells in suspension were separated from large pieces of debris and tissue, pelleted at $40 \times g$, and resuspended in DMEM/Ham's F12 complete medium, seeded in tissue culture-treated flasks and incubated at $37^{\circ} \mathrm{C}, 5 \% \mathrm{CO}_{2}$. Fresh medium was added every 3-4 days until day 10 when microglia and oligodendrocytes were removed from the astroglial bed layer by shaking the flasks on an orbital shaker for $16 \mathrm{~h}$ at $275 \mathrm{rpm}$. The enriched astrocyte cultures were then processed through three rounds of trypsinization and replating to assure elimination of residual microglia. Astrocytes were

\section{Map of CIITA gene constructs:}

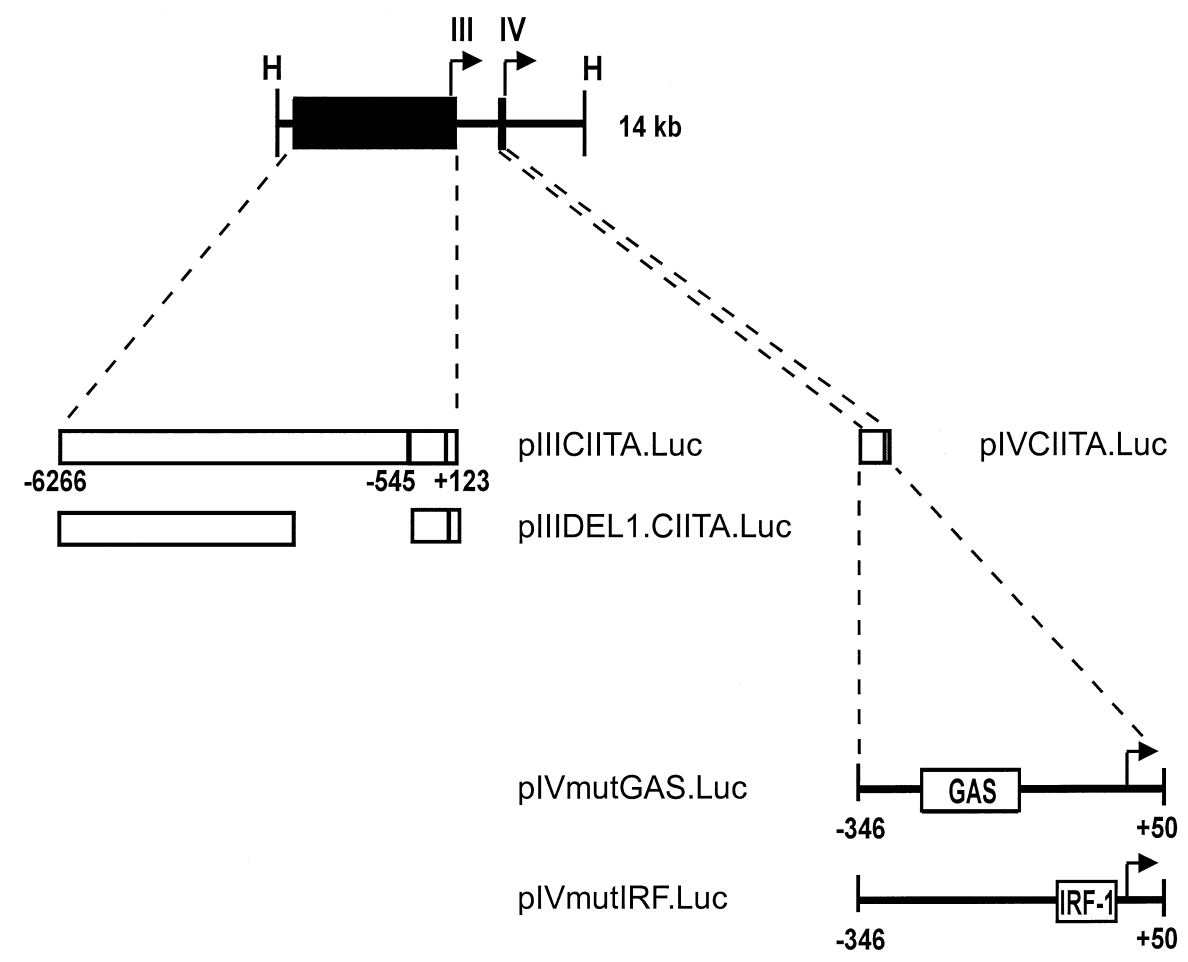

Fig. 1. Map of CIITA gene constructs used. A human genomic library was screened using a PCR-generated probe as previously described (Piskurich et al., 1998). A diagram of a 14-kb HindIII fragment that contains two IFN- $\gamma$-inducible CIITA promoters is shown. Locations of start sites of the upstream promoter (III) and the downstream promoter (IV) are shown by arrows. DNA fragments used in luciferase reporter constructs are shown as white boxes. The region of promoter IV that contains the IRF-1 and STAT1 binding sites is shown. The STAT1 site (GAS element) was mutated from positions - 89 to -84 (TTCTGA mutated to GGAGTC), the IRF-1 binding site was mutated from positions -63 to -59 (AGTGA mutated to CTTAG) as previously described (Piskurich et al., 1999). 
then replated at $2 \times 10^{6}$ cells per $150 \mathrm{~mm}$ tissue culture plates and allowed to expand prior to transfection.

\subsection{Constructs}

The isolation of clones containing the promoter regions of the human CIITA gene as well as the construction of pIIICIITA.Luc (previously p7000CIITA.Luc) and pIIIDEL1.CIITA.Luc (previously p7000-2000CIITA.Luc) have been previously described (Piskurich et al., 1998). The construction of CIITA promoter IV-luciferase reporter (pIVCIITA.Luc) as well as the construction of the IRF-1 mutation (pIVmutIRF.Luc) and gamma activation sequence (GAS) (pIVmutGAS.Luc) mutation have also been described (Piskurich et al., 1999). The sequences of all plasmids have been confirmed by DNA sequencing. The pGL2-Basic plasmid (Promega) (into which all CIITA constructs were cloned) was used as the negative control. A map of CIITA gene constructs is shown in Fig. 1.

\subsection{Transfection}

Primary rat astrocytes and RAW 264.7 cells were transiently transfected by electroporation. Astrocytes $(2 \times$ $10^{6} / 0.3 \mathrm{ml}$ culture medium) or RAW 264.7 cells $(1.6 \times$ $10^{7} / 0.250 \mathrm{ml}$ culture medium) were combined with $10-15$ $\mu \mathrm{g}$ of plasmid DNA and pulsed at $0.20 \mathrm{~V}$ (astrocytes) or $0.23 \mathrm{~V}$ (RAW 264.7), $960 \mu \mathrm{F}$ using a BioRad Gene Pulser. Transfected cells were plated in $10 \mathrm{~mm}$ tissue culture plates and allowed to adhere for approximately $2 \mathrm{~h}$ prior to the addition of the indicated amount of cytokine (IFN- $\gamma$ and/or TNF- $\alpha$ ). For those experiments in which anti-TGF- $\beta$ was used to block endogenous TGF- $\beta, 10$ or $30 \mu \mathrm{g} / \mathrm{ml}$ of antibody was added to the transfected cells 3 $\mathrm{h}$ prior to the addition of IFN- $\gamma$.
Cells transfected with CIITA promoter constructs were harvested after 14-17 h of cytokine treatment, washed twice with PBS, and cell lysates made using cell lysis buffer (Promega, Madison, WI). The protein content of cell extracts was determined using the Bradford assay. The luciferase assay was performed as described (Brasier et al., 1989). Luciferase activity (given as relative light units, RLU) in the samples was quantitated using an EG\&G Berthold LB 953 AutoLumat luminometer. Fold induction was determined by dividing the RLU of IFN- $\gamma$ treated samples by the RLU of untreated samples.

\section{Results}

3.1. IFN-y-inducible CIITA expression in RAW 264.7 macrophages uses both CIITA promoters III and IV

Previous work has demonstrated that CIITA promoter usage determines tissue-specific expression of CIITA and ultimately MHC class II expression. Muhlethaler-Mottet et al. (1997) have shown that IFN- $\gamma$-inducible MHC class II expression is dependent upon the activity of CIITA promoter IV. More recent work from our laboratory has demonstrated that while CIITA promoter III is constitutively active in B-cells, there is an IFN- $\gamma$-inducible element that is located over $2.5-\mathrm{kb}$ upstream of the transcriptional start site and is active in certain cell lines such as 2fTGH fibrosarcoma or U373-MG glioblastoma cells (Piskurich et al., 1998). The transformed murine macrophage cell line, RAW 264.7 (Raschke et al., 1978), was used to assess CIITA promoter activity following IFN- $\gamma$ treatment. These cells demonstrated a strong (2Bfold induction) IFN- $\gamma$ responsiveness of the pIVCIITA.Luc (Fig. 2a) and also exhibited a five- to six-fold induction of
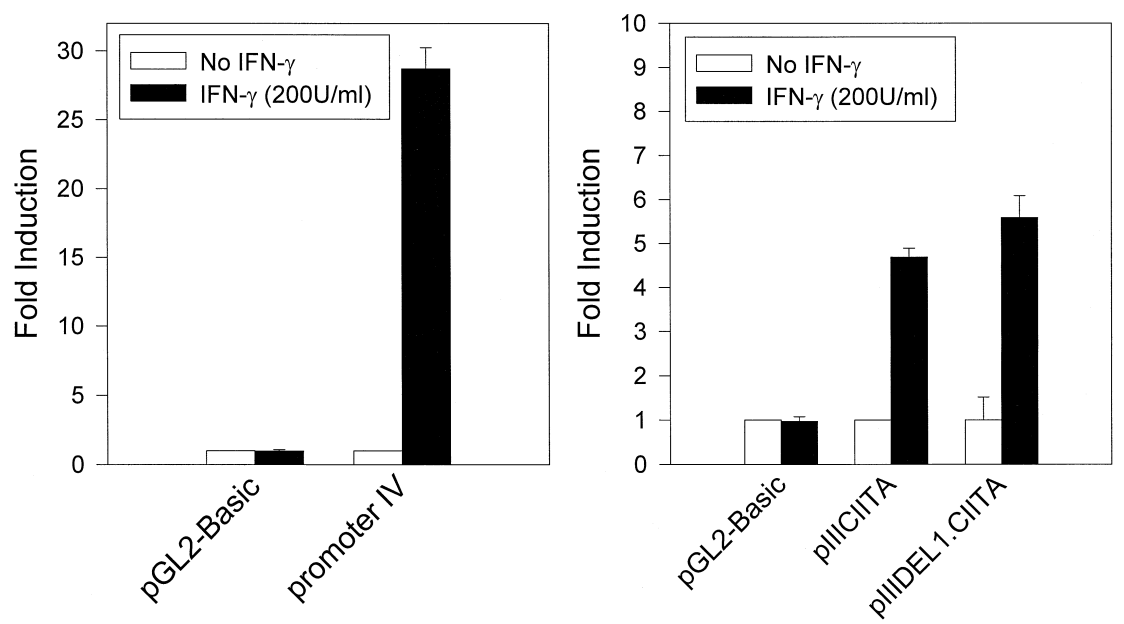

Fig. 2. Both CIITA promoter III and promoter IV are active in RAW 264.7 cells following IFN- $\gamma$ treatment. The murine macrophage line RAW 264.7 cells were transiently transfected with (A) CIITA promoter IV-luciferase reporter construct (see Fig. 1), or (B) CIITA promoter III-luciferase reporter constructs and the negative control plasmid pGL2-Basic as described in Section 2. Cells were treated with or without mouse IFN- $\gamma(200 \mathrm{U} / \mathrm{ml})$, harvested $14 \mathrm{~h}$ later, and luciferase activity determined. Data represent the mean of triplicate cultures and are representative of four separate experiments. 
both the full length (7-kb) promoter III (pIIICIITA.Luc) as well as promoter III lacking the central 2-kb KpnI fragment (pIIIDEL1.CIITA.Luc) (Fig. 2b), indicating that both CIITA promoters III and IV are IFN- $\gamma$-inducible in this cell type. These data parallel our previous analyses of the fibrosarcoma and glioblastoma cell lines (Piskurich et al., 1998).

3.2. IFN- $\gamma$-inducible CIITA expression in primary rat astrocytes is dependent upon promoter IV but not promoter III

Little is known regarding the regulation of IFN- $\gamma$-inducible CIITA expression in astrocytes, thus to determine which CIITA promoters are active in these cells, primary rat astrocytes were transiently transfected with pIVCIITA.Luc. Treatment of transfected cells with 100 $\mathrm{U} / \mathrm{ml}$ rat IFN- $\gamma$ resulted in a five-fold induction in CIITA promoter IV activity over untreated cells (Fig. 3a). To determine if the IFN- $\gamma$-inducible form of promoter III is active in astrocytes, these cells were transiently transfected with pIIICIITA.Luc or pIIIDEL1.CIITA.Luc. Neither of the promoter III constructs exhibited IFN- $\gamma$-inducible activity in primary rat astrocytes indicating that these cells exclusively use promoter IV as the IFN- $\gamma$-inducible CIITA promoter (Fig. 3b).

\subsection{Promoter IV activity in primary rat astrocytes is dependent upon IRF-1 but not STAT1 binding}

Previous reports have demonstrated that CIITA promoter IV activity is dependent upon both STAT1 and IRF-1 proteins binding to their respective sites in the promoter (Muhlethaler-Mottet et al., 1998), while others have recently demonstrated that the IRF-1 site is essential for IFN- $\gamma$-induced promoter IV activity and STAT1 binding to the GAS element only contributed to the inducibility of this promoter (Dong et al., 1999). To confirm the necessity of these DNA binding proteins for CIITA expression in rat astrocytes, cells were transfected with pIVCIITA.Luc constructs specifically mutated in the proximal STAT1 binding site (the GAS element; pmutGAS.Luc) or the proximal IRF-1 binding site (pmutIRF.Luc) (see Fig. 1). Similar to the report of Dong et al., primary rat astrocytes required only IRF-1 binding for IFN- $\gamma$-induced promoter IV. However, our data demonstrate that activation was not at all dependent upon STAT1 binding (Fig. $4 a$ ) as the mutation in this site (pmutGAS.Luc) had no effect on reporter gene expression. In contrast to the rat astrocytes, murine RAW 264.7 cells demonstrated a partial dependence upon STAT1 binding (fold induction dropped from 22 to 12 in two separate experiments) and a complete dependence upon IRF-1 binding for CIITA promoter IV activity (Fig. 4b), indicating that there are cell-type specific differences in the regulation of the same CIITA promoter.

\subsection{IFN- $\gamma$-inducible CIITA promoter IV activity is not augmented in the presence of TNF- $\alpha$}

The exposure of astrocytes to IFN- $\gamma$ in the presence of TNF- $\alpha$ has been shown to synergistically increase MHC class II expression on the cell surface (Benveniste et al., 1989). As the human CIITA promoter IV contains an NK-к B site, this augmentation may be due to an increase in CIITA promoter activity. Thus, we were interested to
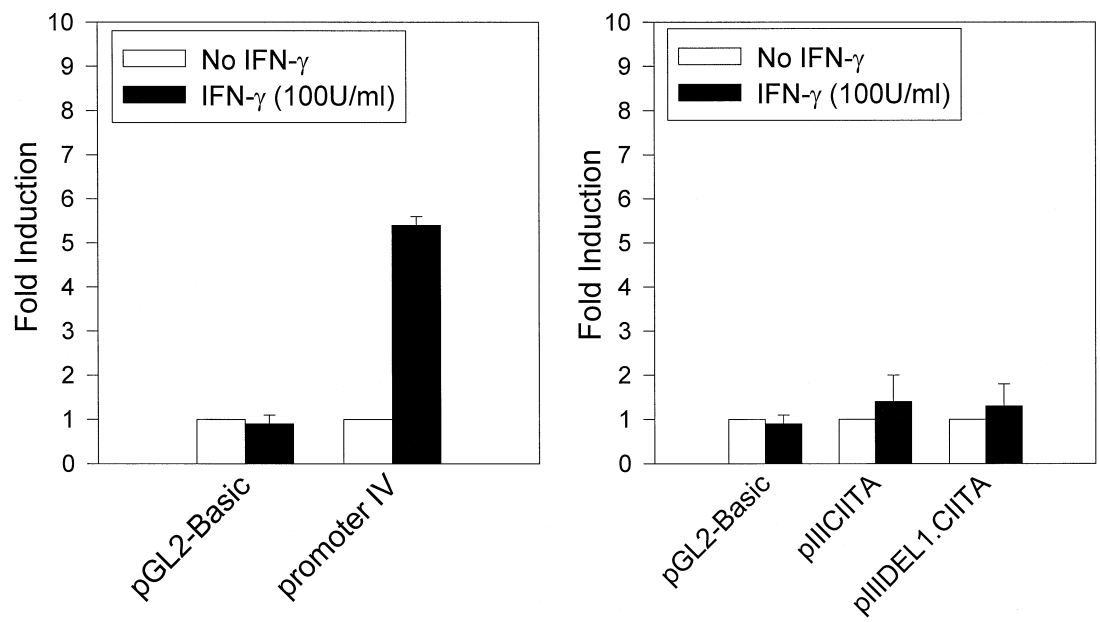

Fig. 3. CIITA promoter usage in primary rat astrocytes following IFN- $\gamma$ treatment. Primary rat astrocytes were transiently transfected with (A) CIITA promoter IV-luciferase reporter construct (see Fig. 1), or (B) CIITA promoter III-luciferase reporter constructs, or the negative control plasmid pGL2-Basic as described in Section 2. Cells were treated with or without rat IFN- $\gamma(100 \mathrm{U} / \mathrm{ml})$, harvested $17 \mathrm{~h}$ later, and luciferase activity determined. Data represent the mean of triplicate cultures and are representative of four separate experiments. 

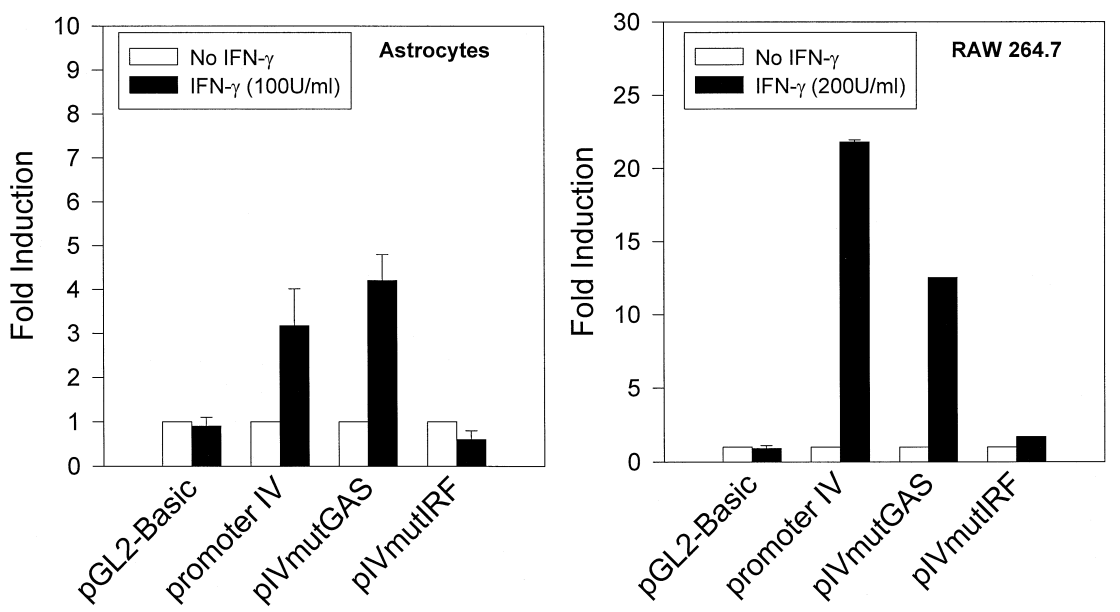

Fig. 4. CIITA promoter IV activity in rat astrocytes requires IRF-1 but not STAT1 binding domains. (A) Primary rat astrocytes or (B) RAW 264.7 cells were transfected with pIVCIITA.Luc specifically mutated at either the IRF-1 or STAT1 binding sites as described in Section 2 (see Fig. 1). Cells were treated with rat IFN- $\gamma(100 \mathrm{U} / \mathrm{ml})$ or mouse IFN- $\gamma(200 \mathrm{U} / \mathrm{ml})$, harvested $17 \mathrm{~h}$ later and luciferase activity determined. Data represent the mean of triplicate cultures and are representative of three separate experiments.

determine if treatment with TNF- $\alpha$ alone induces CIITA promoter III or IV activation or augments IFN- $\gamma$-induced activity of promoter IV. Rat astrocytes were transfected with the pIIIDEL1.CIITA.Luc (this construct was chosen over the full length pIIICIITA.Luc as it demonstrates greater activity following IFN- $\gamma$ treatment in most cell types) or pIVCIITA.Luc and treated with TNF- $\alpha$ (400 $\mathrm{U} / \mathrm{ml})$ alone or in the presence of IFN- $\gamma(100 \mathrm{U} / \mathrm{ml})$. As shown in Fig. 5, the addition of TNF- $\alpha$ had no effect on either promoter III or promoter IV activation. These data indicate that the synergy between TNF- $\alpha$ and IFN- $\gamma$ for

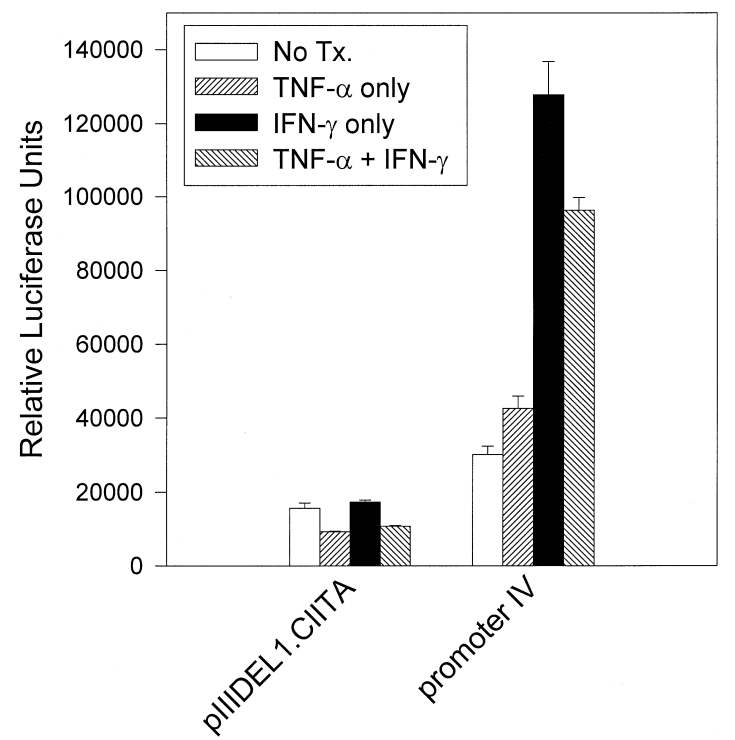

Fig. 5. TNF- $\alpha$ does not enhance IFN- $\gamma$-induced CIITA promoter IV activity in rat astrocytes. Primary rat astrocytes were transfected with pIIIDEL1.CIITA.Luc (promoter III) or pIVCIITA.Luc (promoter IV) constructs and treated with rat IFN- $\gamma(100 \mathrm{U} / \mathrm{ml})$ and/or mouse TNF- $\alpha$ $(500 \mathrm{U} / \mathrm{ml})$. Cells were harvested $17 \mathrm{~h}$ later and luciferase activity determined. Data represent the mean of triplicate cultures and are representative of three separate experiments.
MHC class II protein expression must occur at a point downstream of CIITA induction or independent of CIITA, and likely at the level of the MHC class II promoter itself.

\subsection{Treatment of astrocytes with anti-TGF- $\beta$ does not induce CIITA promoter III activity}

Our laboratory has recently demonstrated that IFN- $\gamma$-induced CIITA promoter III activity is largely inhibited in

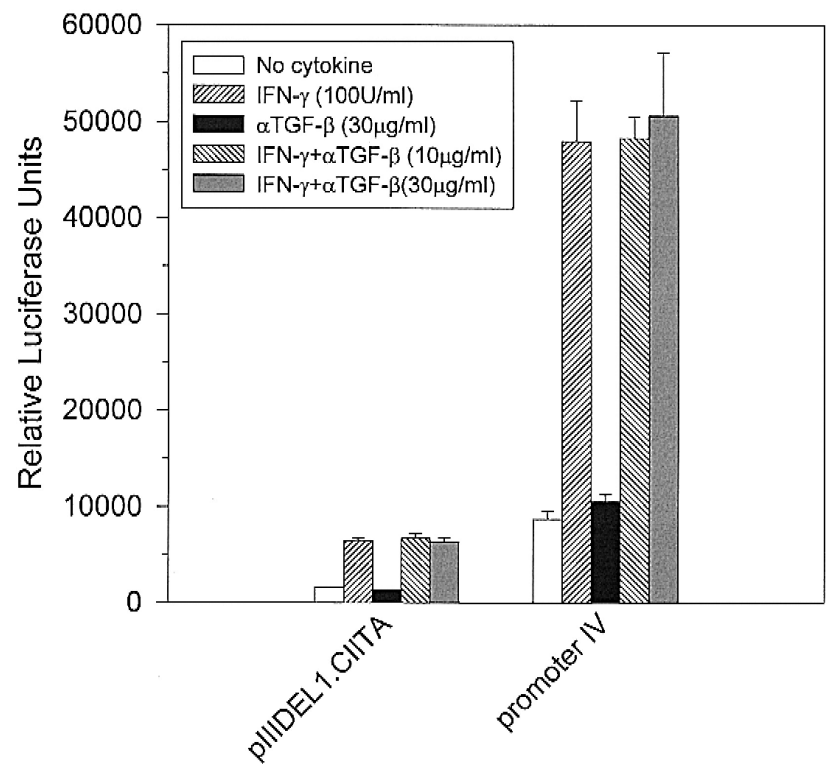

Fig. 6. Lack of promoter III activity in rat astrocytes is not due to the presence of endogenous TGF- $\beta$. Primary rat astrocytes were transfected with pIIIDEL1.CIITA.Luc or pIVCIITA.Luc constructs and incubated in the presence of anti-TGF- $\beta$ (10 or $30 \mu \mathrm{g} / \mathrm{ml}$ ) for $3 \mathrm{~h}$ prior to the addition of rat IFN- $\gamma(100 \mathrm{U} / \mathrm{ml})$. Cells were cultured an additional $17 \mathrm{~h}$ following IFN- $\gamma$ treatment, harvested, and luciferase activity determined. Data represent the mean of triplicate cultures and are representative of two separate experiments. 
the presence of TGF- $\beta$; promoter IV is also inhibited by TGF- $\beta$ but to a lesser extent (Piskurich et al., 1999). Because stimulated astrocytes are capable of secreting TGF- $\beta$, it was possible that the presence of this cytokine in the astrocyte cultures was inhibiting the activity of pIIIDEL1.CIITA.Luc. To address this possibility, primary rat astrocytes were transiently transfected with either pIIIDEL1.CIITA.Luc or pIVCIITA.Luc, incubated in the presence of anti-TGF- $\beta$ for $2 \mathrm{~h}$, then treated with IFN- $\gamma$ as previously described. If endogenous TGF- $\beta$ was affecting CIITA promoter III activity in the rat astrocytes, then it would be expected that incubation in the presence of anti-TGF- $\beta$ would result in an increase of CIITA promoter III activity in the presence of IFN- $\gamma$. As shown in Fig. 6, however, the addition of anti-TGF- $\beta$ at two different concentrations had no effect on the activity of either pIIIDEL1.CIITA.Luc or pIVCIITA.Luc, indicating that the presence of endogenous TGF- $\beta$ is likely not the reason for lack of CIITA promoter III activity in these cells.

\section{Discussion}

MHC class II gene regulation in different cell types can be separated into two basic categories: those that exhibit constitutive expression and those that exhibit cytokine-inducible expression. The control of MHC class II expression lies at the transcriptional level and is dependent in part upon the activities of the non-DNA binding, transcriptional transactivator, and master regulator, CIITA. The expression of CIITA is complex, depending upon the activity of four distinct promoter regions (MuhlethalerMottet et al., 1997). Each of the promoters has its own unique transcriptional start site resulting in three different CIITA isotypes (promoter II has not been ascribed a function in humans and has not yet been cloned in mice). Which of the three different CIITA transcripts is produced may have a direct bearing on the ability to transactivate MHC class II genes in different cell types.

Several lines of evidence have made it clear that various cell types exhibit differential CIITA promoter usage with constitutive expression by dendritic cells and B-cells being controlled by CIITA promoters I and III, respectively, while most IFN- $\gamma$-inducible cells require promoter III and/or promoter IV (Muhlethaler-Mottet et al., 1997; Piskurich et al., 1998). We were interested in defining CIITA promoter usage in primary rat astrocytes in order to gain a better understanding of the molecular control of MHC class II in cells of the CNS. Our data demonstrate that astrocytes utilize only CIITA promoter IV following stimulation by IFN- $\gamma$, in contrast to the murine macrophage cell line, RAW 264.7, that utilizes both CIITA promoters III and IV following IFN- $\gamma$ stimulation. These data are in agreement with another recent report (Soos et al., 1998) in which astrocytes were found to express CIITA promoter IV mRNA. Since the submission of this manuscript, an- other report showed that astrocytes utilize a CIITA promoter IV/reporter construct (Dong et al., 1999). Our data extend these findings to provide a comparison of promoter III vs. promoter IV usage in astrocytes, and demonstrate that CIITA promoter III activity is not induced in astrocytes in the presence of IFN- $\gamma$. We do not believe that the lack of CIITA promoter III activity in rat astrocytes is attributable to technical issues such as poor transfection efficiency of this reporter construct since all transfections using promoter III or promoter IV reporter constructs were done in parallel, using the same astrocyte cell preparations. In addition, other cell lines (the RAW 264.7 in particular) demonstrated excellent promoter III activity indicating that there was nothing inherently wrong with that particular plasmid preparation. Rather, we believe that the significance of our finding may lie in the regulation of MHC class II expression by certain cytokines. For example, CIITA promoter III is more sensitive to the downregulatory effects of the anti-inflammatory cytokine TGF- $\beta$ (Piskurich et al., 1999) compared to promoter IV; since astrocytes secrete TGF- $\beta$ upon stimulation it would not make physiological sense to use CIITA promoter III following IFN- $\gamma$ stimulation as this might result in immediate downregulation of MHC class II. It is also possible that the difference is due to the fact that we are comparing primary rat cells to mouse cells that have been transformed and cultured for extended periods of time. To address this possibility, it would be ideal to investigate CIITA promoter usage in primary rat microglia, however, these cells are extremely difficult to transfect. The most likely explanation is that macrophage are important cells for antigen presentation in the peripheral immune system while the primary role for astrocytes is to maintain homeostasis in the CNS. Although astrocytes have been shown to be able to present antigen in certain (in vitro) situations, they are not professional APCs. Thus the usage of both CIITA promoters III and IV may be reserved for APCs such as macrophage, while promoter IV is largely utilized in cell types that exhibit IFN- $\gamma$-inducible MHC class II but are inefficient at, yet capable of, antigen presentation in extenuating circumstances such as during autoimmune disease.

Using the Me67.8 melanoma cell line, MuhlethalerMottet et al. (1998) demonstrated that CIITA promoter IV activity is dependent upon three distinct elements of the promoter: the E-box as well as the IRF-1 and STAT1 binding sites. In contrast, a recently published report from Dong et al. (1999) demonstrated that while the IRF-1 site was necessary for CIITA promoter IV activity, the STAT1 site only contributed to the IFN- $\boldsymbol{\gamma}$-inducibility of promoter IV. We here determined the necessity for the proximal IRF-1 and STAT1 binding sites in CIITA promoter IV following IFN- $\gamma$ stimulation of rat astrocytes in our system. Our data demonstrate that in rat astrocytes, IRF-1 is, indeed, essential for CIITA promoter IV activity but that activity was not at all dependent upon STAT1 binding to the GAS element. This is in contrast to the RAW 264.7 
cells which exhibit some dependency on the GAS element. Our data suggest that IFN- $\gamma$ stimulation of rat astrocytes results in a different intracellular signaling cascade that does not require STAT1 activation for CIITA promoter activity. The IRF-1 promoter also contains a GAS element and is generally thought to be dependent upon STAT1 for its transcription (Rein et al., 1994) thus it is likely that STAT1 functions to induce IRF-1 expression but is not acting directly upon CIITA promoter IV in rat astrocytes. These data again support a model for differential MHC class II activation pathways in different cell types.

A host of cytokines have been shown to both positively and negatively affect MHC class II expression. The pro-inflammatory cytokine, TNF- $\alpha$ acts synergistically with IFN- $\gamma$ to upregulate MHC class II expression on many cell types including cells derived from the CNS such as microglia and astrocytes (Benveniste et al., 1989). Importantly, this synergism appears to exert its affect at a point downstream, or independent of CIITA promoter activation as the addition of TNF- $\alpha$ in the presence or absence of IFN- $\gamma$ had no affect on CIITA promoter III activity in rat astrocytes, nor did it enhance IFN- $\gamma$-induction of CIITA promoter IV in these cells. Additionally, the anti-inflammatory cytokines such as IL-4, IL-10, and TGF- $\beta$ have been shown to downregulate MHC class II expression on a number of different cell types (de Waal Malefyt et al., 1991; Devajyothi et al., 1993; Frei et al., 1994; Benveniste et al., 1994; Morga and Heuschling, 1996). At what level of MHC class II gene expression these cytokines are having their affect has not been completely elucidated, however, recent evidence has shown that TGF- $\beta$ inhibits accumulation of CIITA mRNA transcripts (Lee et al., 1997) while data from our laboratory has definitively shown that TGF- $\beta$ acts directly on the CIITA promoter to inhibit its activity (Piskurich et al., 1999). This inhibition of activity appeared to be promoter-specific in that CIITA promoter III was far more sensitive than promoter IV to the effects of TGF- $\beta$. Since TGF- $\beta$ has been shown to be produced by activated astrocytes (Peress et al., 1996; Hailer et al., 1998; Vivien et al., 1998), we were concerned about the possibility that endogenous TGF- $\beta$ may be masking CIITA promoter III activity in the astrocytes. The addition of neutralizing anti-TGF- $\beta$ antibodies to the transfection cultures, however, had no affect on CIITA promoter usage. These data indicate that promoter IV is the sole CIITA promoter used in astrocytes and that lack of promoter III activation cannot be accounted for by the presence of inhibitory endogenous TGF- $\beta$.

Our data provide new and important evidence for the differential regulation of MHC class II gene expression in specialized cell types. These data suggest that during immune responses in the CNS, astrocytes are capable of activating the machinery necessary for MHC class II expression but that the pathways used for such expression may be divergent from those typically followed in professional APCs such as B-cells or macrophages. Thus, it may be possible to exploit these differences in an attempt to specifically inhibit MHC class II expression in cases of autoimmune dysfunction of the CNS, such as multiple sclerosis where expression of MHC class II is detrimental.

\section{Acknowledgements}

This work was supported by National Multiple Sclerosis Society (NMSS) Grant RG-1785, NIH Grant NS34190, and NMSS Fellowships FA-1307-A-2, FG-1173-A-1, and FA-1109-A-1. K.M.N., J.F.P., and R.P.H. are postdoctoral fellows of the National Multiple Sclerosis Society. J.P.Y.T. is an American Cancer Society Faculty Awardee.

\section{References}

Benveniste, E.N., Sparacio, S.M., Bethea, J.R., 1989. Tumor necrosis factor- $\alpha$ enhances interferon- $\gamma$-mediated class II antigen expression on astrocytes. J. Neuroimmunol. 25, 209-219.

Benveniste, E.N., Kwon, J., Chung, W.J., Sampson, J., Pandya, K., Tang, L.P., 1994. Differential modulation of astrocyte cytokine gene expression by TGF- $\beta$. J. Immunol. 153, 5210-5221.

Birnbaum, G., Kotilinek, L., 1990. Immunologic differences in murine glial cells and their association with susceptibility to experimental allergic encephalomyelitis. J. Neuroimmunol. 26, 119-129.

Borrow, P., Nash, A.A., 1992. Susceptibility to Theiler's virus-induced demyelinating disease correlates with astrocyte class II induction and antigen presentation. Immunology 76, 133-139.

Brasier, A.R., Tate, J.E., Habener, J.F., 1989. Optimized use of the firefly luciferase assay as a reporter gene in mammalian cell lines. Biotechnology 7, 1116-1122.

Chang, C.H., Flavell, R.A., 1995. Class II transactivator regulates the expression of multiple genes involved in antigen presentation. J. Exp. Med. 181, 765-767.

Devajyothi, C., Kalvakolanu, I., Babcock, G.T., Vasavada, H.A., Howe, P.H., Ransohoff, R.M., 1993. Inhibition of interferon-gamma-induced major histocompatibility complex class II gene transcription by interferon-beta and type beta 1 transforming growth factor in human astrocytoma cells. Definition of cis-element. J. Biol. Chem. 268, 18794-18800

de Waal Malefyt, R., Haanen, J., Spits, H., Roncarolo, M.G., te Velde, A., Figdor, C., Johnson, K., Kastelein, R., Yssel, H., de Vries, J.E., 1991. Interleukin 10 (IL-10) and viral IL-10 strongly reduce antigenspecific human $\mathrm{T}$ cell proliferation by diminishing the antigen-presenting capacity of monocytes via downregulation of class II major histocompatibility complex expression. J. Exp. Med. 174, 915-924.

Dong, Y., Rohn, W.M., Benveniste, E.N., 1999. IFN- $\gamma$ regulation of the type IV class II transactivator promoter in astrocytes. J. Immunol. $162,4731-4739$.

Fierz, W., Endler, B., Reske, K., Wekerle, H., Fontana, A., 1985. Astrocytes as antigen-presenting cells: I. Induction of Ia antigen expression on astrocytes by $\mathrm{T}$ cells via immune interferon and its effect on antigen presentation. J. Immunol. 134, 3785-3793.

Fontana, A., McAdam, K.P., Kristensen, F., Weber, E., 1983. Biological and biochemical characterization of an interleukin 1-like factor from rat C6 glioma cells. Eur. J. Immunol. 13, 685-689.

Fontana, A., Erb, P., Pircher, H., Zinkernagel, R., Weber, E., Fierz, W., 1986. Astrocytes as antigen-presenting cells: Part II. Unlike H-2K-dependent cytotoxic T cells, H-2Ia-restricted T cells are only stimulated in the presence of interferon-gamma. J. Neuroimmunol. 12, 15-28.

Fontes, J.D., Jabrane-Ferrat, N., Joth, C.R., Peterlin, B.M., 1996. Binding 
and cooperative interactions between two B cell-specific transcriptional coactivators. J. Exp. Med. 183, 2517-2521.

Frei, K., Bodmer, S., Schwerdel, C., Fontana, A., 1985. Astrocytes of the brain synthesize interleukin 3-like factors. J. Immunol. 135, 40444047.

Frei, K., Malipiero, U.V., Leist, T.P., Zinkernagel, R.M., Schwab, M.E., Fontana, A., 1989. On the cellular source and function of interleukin 6 produced in the central nervous system in viral diseases. Eur. J. Immunol. 19, 689-694.

Frei, K., Lins, H., Schwerdel, C., Fontana, A., 1994. Antigen presentation in the central nervous system. The inhibitory effect of IL-10 on MHC class II expression and production of cytokines depends on the inducing signals and the type of cell analyzed. J. Immunol. 152, 2720-2728.

Friedmann, A., Frankel, G., Lorch, Y., Steinman, L., 1987. Monoclonal anti-I-A antibody reverses chronic paralysis and demyelination in Theiler's virus-infected mice: critical importance of timing of treatment. J. Virol. 61, 898-903.

Glimcher, L.H., Kara, C.J., 1992. Sequences and factors: a guide to MHC class-II transcription. Annu. Rev. Immunol. 10, 13-49.

Hailer, N.P., Heppner, F.L., Haas, D., Nitsch, R., 1998. Astrocytic factors deactivate antigen presenting cells that invade the central nervous system. Brain Pathol. 8, 459-474.

Hartung, H.P., Heininger, K., Toyka, K.V., 1988. Primary rat astroglial cultures can generate leukotriene B4. J. Neuroimmunol. 19, 237-243.

Hellendall, R.P., Ting, J.P., 1997. Differential regulation of cytokine-induced major histocompatibility complex class II expression and nitric oxide release in rat microglia and astrocytes by effectors of tyrosine kinase, protein kinase C, and cAMP. J. Neuroimmunol. 74, 19-29.

Jonker, M., van Lambalgen, R., Mitchell, D.J., Durham, S.K., Steinman, L., 1988. Successful treatment of EAE in rhesus monkeys with MHC class II specific monoclonal antibodies. J. Autoimmun. 1, 399-414.

Kretsovali, A., Agalioti, T., Spilianakis, C., Tzortzakaki, E., Merika, M., Papamatheakis, J., 1998. Involvement of CREB binding protein in expression of major histocompatibility complex class II genes via interaction with the class II transactivator. Mol. Cell. Biol. 18, 6777-6783

Lee, Y.-J., Han, Y., Lu, H.-T., Nguyen, V., Qin, H., Howe, P.H., Hocevar, B.A., Boss, J.M., Ransohoff, R.M., Benveniste, E.N., 1997. TGF- $\beta$ suppresses IFN- $\gamma$ induction of class II MHC gene expression by inhibiting class II transactivator messenger RNA expression. J. Immunol. 158, 2065-2075.

Lennon, A.M., Ottone, C., Rigaud, G., Deaven, L.L., Longmire, J., Fellous, M., Bono, R., Alcaide-Loridan, C., 1997. Isolation of a B-cell-specific promoter for the human class II transactivator. Immunogenetics 45, 266-273.

Male, D., Pryce, G., 1989. Induction of Ia molecules on brain endothelium is related to susceptibility to experimental allergic encephalomyelitis. J. Neuroimmunol. 21, 87-90.

Massa, P.T., Brinkmann, R., ter Meulen, V., 1987a. Inducibility of Ia antigen on astrocytes by murine coronavirus JHM is rat strain dependent. J. Exp. Med. 166, 259-264

Massa, P.T., ter Meulen, V., Fontana, A., 1987b. Hyperinducibility of Ia antigen on astrocytes correlates with strain-specific susceptibility to experimental autoimmune encephalomyelitis. Proc. Natl. Acad. Sci. U.S.A. 84, 4219-4223.

Matsushima, G.K., Taniike, M., Glimcher, L.H., Grusby, M.J., Frelinger, J.A., Suzuki, K., Ting, J.P., 1994. Absence of MHC class II molecules reduces CNS demyelination, microglial/macrophage infiltration, and twitching in murine globoid cell leukodystrophy. Cell 78, 645-656.

McCarthy, K.D., De Vellis, J., 1980. Preparation of separate astroglial and oligodendroglial cell cultures from rat cerebral tissue. J. Cell Biol. $85,890-902$.

Morga, E., Heuschling, P., 1996. Interleukin-4 down-regulates MHC class II antigens on cultured rat astrocytes. Glia 17, 175-179.

Moses, H., Sasaki, A., Ting, J.P., 1991. Identification of an interferon- gamma-responsive element of a class II major histocompatibility gene in rat type 1 astrocytes. J. Neuroimmunol. 31, 273-278.

Muhlethaler-Mottet, A., Otten, L.A., Steimle, V., Mach, B., 1997. Expression of MHC class II molecules in different cellular and functional compartments is controlled by differential usage of multiple promoters of the transactivator CIITA. EMBO J. 16, 2851-2860.

Muhlethaler-Mottet, A., Di Berardino, W., Otten, L.A., Mach, B., 1998. Activation of the MHC class II transactivator CIITA by interferon- $\gamma$ requires cooperative interaction between Stat1 and USF-1. Immunity 8, 157-166.

Peress, N.S., Perillo, E., Seidman, R.J., 1996. Glial transforming growth factor (TGF)-beta isotypes in multiple sclerosis: differential glial expression of TGF-beta 1, 2 and 3 isotypes in multiple sclerosis. J. Neuroimmunol. 71, 115-123.

Piskurich, J.F., Wang, Y., Linhoff, M.W., White, L.C., Ting, J.P.-Y., 1998. Identification of distinct regions of $5^{\prime}$ flanking DNA that mediate constitutive, IFN- $\gamma$, STAT1, and TGF- $\beta$-regulated expression of the class II transactivator gene. J. Immunol. 160, 233-240.

Piskurich, J.F., Linhoff, M.W., Wang, Y., Ting, J.P.-Y., 1999. Two distinct gamma interferon-inducible promoters of the major histocompatibility complex class II transactivator gene are differentially regulated by STAT1, interferon regulatory factor $\mathrm{I}$, and transforming growth factor $\beta$. Mol. Cell. Biol. 19, 431-440.

Raschke, W.C., Baird, S., Ralph, P., Nanoinz, I., 1978. Functional macrophage cell lines transformed by Abelson leukemia virus. Cell $15,261-267$

Rein, T., Muller, M., Zorbas, H., 1994. In vivo footprinting of the IRF-1 promoter: inducible occupation of a GAS element next to a persistent structural alteration of the DNA. Nucleic Acids Res. 22, 3033-3037.

Riley, J.L., Westerheide, S.D., Price, J.A., Brown, J.A., Boss, J.M., 1995. Activation of class II MHC genes requires both the $\mathrm{X}$ box region and the class II transactivator (CIITA). Immunity 2, 533-543.

Robbins, D.S., Shirazi, Y., Drysdale, B.E., Lieberman, A., Shin, H.S., Shin, M.L., 1987. Production of cytotoxic factor for oligodendrocytes by stimulated astrocytes. J. Immunol. 139, 2593-2597.

Sasaki, A., Levison, S.W., Ting, J.P., 1989. Comparison and quantitation of Ia antigen expression on cultured macroglia and ameboid microglia from Lewis rat cerebral cortex: analyses and implications. J. Neuroimmunol. 25, 63-74.

Sasaki, A., Levison, S.W., Ting, J.P., 1990. Differential suppression of interferon-gamma-induced Ia antigen expression on cultured rat astroglia and microglia by second messengers. J. Neuroimmunol. 29, $213-222$

Sawada, M., Kondo, N., Suzumura, A., Marunouchi, T., 1989. Production of tumor necrosis factor-alpha by microglia and astrocytes in culture. Brain Res. 491, 394-397.

Scholl, T., Mahanta, S.K., Strominger, J.L., 1997. Specific complex formation between the type II bare lymphocyte syndrome-associated transactivators CIITA and RFX5. Proc. Natl. Acad. Sci. U.S.A. 94, 6330-6334.

Smith, R.M., Morgan, A., Wraith, D.C., 1994. Anti-class II MHC antibodies prevent and treat EAE without APC depletion. Immunology $83,1-8$.

Soos, J.M., Morrow, J., Ashley, T.A., Szente, B.E., Bikoff, E.K., Zamvil, S.S., 1998. Astrocytes express elements of the class II endocytic pathway and process central nervous system autoantigen for presentation to encephalitogenic T cells. J. Immunol. 161, 5959-5966.

Sriram, S., Steinman, L., 1983. Anti I-A antibody suppresses active encephalomyelitis: treatment model for diseases linked to IR genes. J. Exp. Med. 158, 1362-1367

Sriram, S., Topham, D.J., Carroll, L., 1987. Haplotype-specific suppression of experimental allergic encephalomyelitis with anti-IA antibodies. J. Immunol. 139, 1485-1489.

Steimle, V., Siegrist, C.A., Mottet, A., Lisowska-Grospierre, B., Mach, B., 1994. Regulation of MHC class II expression by interferon-gamma mediated by the transactivator gene CIITA. Science 265, 106-109. 
Steinman, L., 1990. The use of monoclonal antibodies for treatment of autoimmune disease. J. Clin. Immunol. 10, 30-38.

Tedeschi, B., Barrett, J.N., Keane, R.W., 1986. Astrocytes produce interferon that enhances the expression of $\mathrm{H}-2$ antigens on a subpopulation of brain cells. J. Cell Biol. 102, 2244-2253.

Vivien, D., Bernaudin, M., Buisson, A., Divoux, D., MacKenzie, E.T., Nouvelot, A., 1998. Evidence of type I and type II transforming growth factor-beta receptors in central nervous tissues: changes induced by focal cerebral ischemia. J. Neurochem. 70, 2296-2304.
Welsh, J., Sapatino, B., Rosenbaum, B., Smith, R., Linthicum, S., 1993. Correlation between susceptibility to demyelination and interferongamma induction of major histocompatibility complex class II antigens on murine cerebrovascular endothelial cells. J. Neuroimmunol. 48, 91-97.

Wong, G.H., Bartlett, P.F., Clark-Lewis, I., Battye, F., Schrader, J.W., 1984. Inducible expression of H-2 and Ia antigens on brain cells. Nature 310, 688-691. 